\title{
Neuropsychological Performance of Egyptian Children with Autism Spectrum Disorder and Attention Deficit Hyperactivity Disorder
}

\author{
Sherin Elsheikh"1,2,3, Sanna Kuusikko-Gauffin1, Soile Loukusa4, Manal Omar5, Geylan Riad6, \\ Hanna Ebeling1,7, Irma Moilanen ${ }^{1,7}$ \\ ${ }^{1}$ PEDEGO Research Unit, Child Psychiatry, University of Oulu, Oulu, Finland \\ ${ }^{2}$ Child Psychiatry Unit, Abbassia Mental Hospital, Cairo, Egypt \\ ${ }^{3}$ Centre for Arctic Medicine, Thule Institute, University of Oulu, Oulu, Finland \\ ${ }^{4}$ Research Unit of Logopedics, Child Language Research Center, University of Oulu, Oulu, Finland \\ ${ }^{5}$ Institute of Postgraduate Childhood Studies, Ain Shams University, Cairo, Egypt \\ ${ }^{6}$ Faculty of Arts, Psychology Department, Helwan University, Cairo, Egypt \\ ${ }^{7}$ Clinic of Child Psychiatry, Oulu University Hospital, Oulu, Finland \\ Email: sherinelsheikh@gmail.com
}

How to cite this paper: Elsheikh, S., Kuusikko-Gauffin, S., Loukusa, S., Omar, M., Riad, G., Ebeling, H., \& Moilanen, I. (2017) Neuropsychological Performance of Egyptian Children with Autism Spectrum Disorder and Attention Deficit Hyperactivity Disorder. Psychology, 8, 1280-1300. https://doi.org/10.4236/psych.2017.89083

Received: April 20, 2017

Accepted: July 10, 2017

Published: July 13, 2017

Copyright $\odot 2017$ by authors and Scientific Research Publishing Inc. This work is licensed under the Creative Commons Attribution International License (CC BY 4.0).

http://creativecommons.org/licenses/by/4.0/

\begin{abstract}
This study examined the neuropsychological functioning in autism spectrum disorder (ASD), attention deficit hyperactivity disorder (ADHD), and comorbid ASD and ADHD (ASD + ADHD), using five domains of the Developmental Neuropsychological Assessment (NEPSY): Attention and Executive Functions, Language, Visuospatial Processing, Sensorimotor Functions, and Memory and Learning. The participants were 6- to 12- year-old Egyptian children with ASD $(n=17)$, ASD + ADHD $(n=15)$, ADHD $(n=37)$, and typical development (TD; $n=29$ ). TD children scored highest on the NEPSY domains, then children with ADHD, followed by children with ASD and ASD + ADHD. Children with ASD or ASD + ADHD performed significantly poorer than TD children on all NEPSY domains. Children with ADHD exhibited significantly poorer performance than TD children on NEPSY domains of Attention and Executive Function, Language, and Memory and Learning. Also, both ASD and ASD + ADHD groups scored significantly lower than ADHD group on all other NEPSY domains except Visuospatial Processing. There were no significant differences between ASD and ASD + ADHD groups on NEPSY. Compared to TD children, our results suggest that ADHD symptoms in children with ASD may worsen the ability to plan, hand motor coordination, and memorizing names. Nevertheless, the presence of ADHD symptoms may mitigate the difficulties that children with ASD exhibit in other neuropsychological areas, such as verbal fluency, hand praxis, finger gnosis,
\end{abstract}


and face memory.

\section{Keywords}

ASD, ADHD, NEPSY, Cognitive Development, Neuropsychological

Performance, Executive Function, Comorbidity, Children

\section{Introduction}

Deficits in neuropsychological abilities have been described in both autism spectrum disorder (ASD) and attention deficit hyperactivity disorder (ADHD). The diagnostic criteria for ASD and ADHD are distinct; children with ASD are characterized by impaired social and communication skills and by restricted repetitive stereotyped pattern of behavior, whereas children with ADHD mainly present symptoms of inattention, hyperactivity and impulsivity (APA, 2013; WHO, 1993). However, it is not uncommon to have overlapping symptoms of ADHD and ASD in one child, such as deficits in attention, behavioral problems and social difficulties and several studies demonstrated that about $20 \%-50 \%$ of children with ADHD meet the diagnostic criteria for ASD and about $30 \%-80 \%$ of children with ASD meet the diagnostic criteria for ADHD (Mattila et al., 2010; Rommelse, Franke, Geurts, Hartman, \& Buitelaar, 2010). There have been debates, over the last decade about overlapping symptoms and comorbidity of ASD and ADHD (Ames \& White, 2011; Gargaro, Rinehart, Bradshaw, Tonge, \& Sheppard, 2011; Reiersen \& Todd, 2008; Ronald, Simonoff, Kuntsi, Asherson, \& Plomin, 2008; Taurines et al., 2012), leading to acceptance of dual diagnosis of ASD and ADHD in DSM-5 (APA, 2013).

There are no published studies comparing different domains of the neuropsychological profile (attention and executive function, language, visuospatial abilities, sensorimotor abilities, and memory and learning domains) in children with ASD, ADHD and comorbid ASD and ADHD (ASD + ADHD). Previous studies, which have evaluated these domains, separately included children with ASD (Barron-Linnankoski et al., 2015; Hooper, Poon, Marcus, \& Fine, 2006; Narzisi, Muratori, Calderoni, Fabbro, \& Urgesi, 2013; Williams, Goldstein, \& Minshew, 2006a) or ADHD (Rizzutti et al., 2008; Rucklidge \& Tannock, 2002). Further, studies that investigated the differences of neuropsychological functioning between children with ASD and ADHD, only analyzed some selected neuropsychological abilities, such as sustained attention (Johnson et al., 2007), inhibitory control (Buhler, Bachmann, Goyert, Heinzel-Gutenbrunner, \& KampBecker, 2011), or executive function (Geurts, Verte, Oosterlaan, Roeyers, \& Sergeant, 2004; Goldberg et al., 2005; Happé, Booth, Charlton, \& Hughes, 2006; Matsuura et al., 2014). In these studies, children with ADHD demonstrated deficits in sustained attention and response inhibition, compared to children with ASD (Johnson et al., 2007; Buhler et al., 2011). Results of studies examining response inhibition, planning and cognitive flexibility (i.e., shifting attention) in 
ASD are not, however, consistent (Geurts et al., 2004; Goldberg et al., 2005; Happé et al., 2006; Johnson et al., 2007; Van der Meer et al., 2012). Similarly, studies evaluating the influence of comorbidity in ASD + ADHD diagnoses focused on individual abilities, such as attention (Sinzig, Bruning, Morsch, \& Lehmkuhl, 2008a), inhibitory control (Takeuchi et al., 2013), or executive function (Sinzig, Morsch, Bruning, Schmidt, \& Lehmkuhl, 2008b; Yerys, et al., 2009; Tye et al., 2014) but not the wider neuropsychological profile. Sinzig and colleagues (2008b) found that children with ASD + ADHD showed deficit in inhibiting a pre-potent response and inhibition of an ongoing response in addition to deficits in planning and flexibility, but there were no indication that children with ASD + ADHD would have a specific attention profile, when compared to pure ASD (Sinzig et al., 2008a). Tye and colleagues (2014) suggested that children with ASD + ADHD presented an additive combination of deficits of both disorders. It is also noteworthy to mention that majority of neuropsychological studies on individuals with ASD, ADHD, and ASD + ADHD were conducted in the Western World with no data originating from the Middle East.

With the above-mentioned gaps in literature in mind, we established a prospective comparative study to examine the similarities and differences of the neuropsychological performance between Egyptian children with ASD, ASD + ADHD, ADHD and TD, using a single multi-domain neuropsychological battery (the NEPSY, Korkman, 2000).

\section{Method}

\subsection{Participants and Procedure}

A total of sixty-nine Arabic speaking Egyptian children with ASD ( $n=17)$, ASD $+\operatorname{ADHD}(\mathrm{n}=15)$, and $\operatorname{ADHD}(\mathrm{n}=37)$ participated in the study with their TD counterparts $(n=29)$. Table 1 details the demographic information of the participants. The diagnostic groups were recruited through the child psychiatry outpatient clinic of the Abbassia Mental Hospital-a tertiary referral public hospital (ASD, $n=6$; ASD + ADHD, $n=7$; ADHD, $n=16$ ), and a private child psychiatry clinic in Cairo (ASD, $n=11$; ASD + ADHD, $n=8$; ADHD, $n=21$ ), over two years (2007 and 2008). The TD children were randomly selected from public $(n=12)$ and private $(n=17)$ mainstream schools in Cairo. Children were recruited from public and private sectors, so that the study groups would be representative of different socioeconomic statuses.

Psychiatric diagnoses were set according to International Statistical Classification of Diseases and Related Health Problems, $10^{\text {th }}$ revision (ICD-10) (WHO, 1993 ) and confirmed with Autism Diagnostic Interview (ADI-R; Lord, Rutter, \& Le Couteur, 1995) and Autism Diagnostic Observation Schedule (ADOS; Lord, Rutter, Dilavore, \& Risi, 2000). The Schedule for Affective Disorders and Schizophrenia for School-Age Children/Present and Lifetime Version (K-SADS-PL; Kaufman et al. 1997; based on the Diagnostic and Statistical Manual of Mental Disorders, $4^{\text {th }}$ Edition, DSM-IV (APA, 2013) was used to confirm the diagnosis of ADHD. Severe developmental disorders (e.g., specific language impairment, 
Table 1. Demographic and psychometric data of study participants.

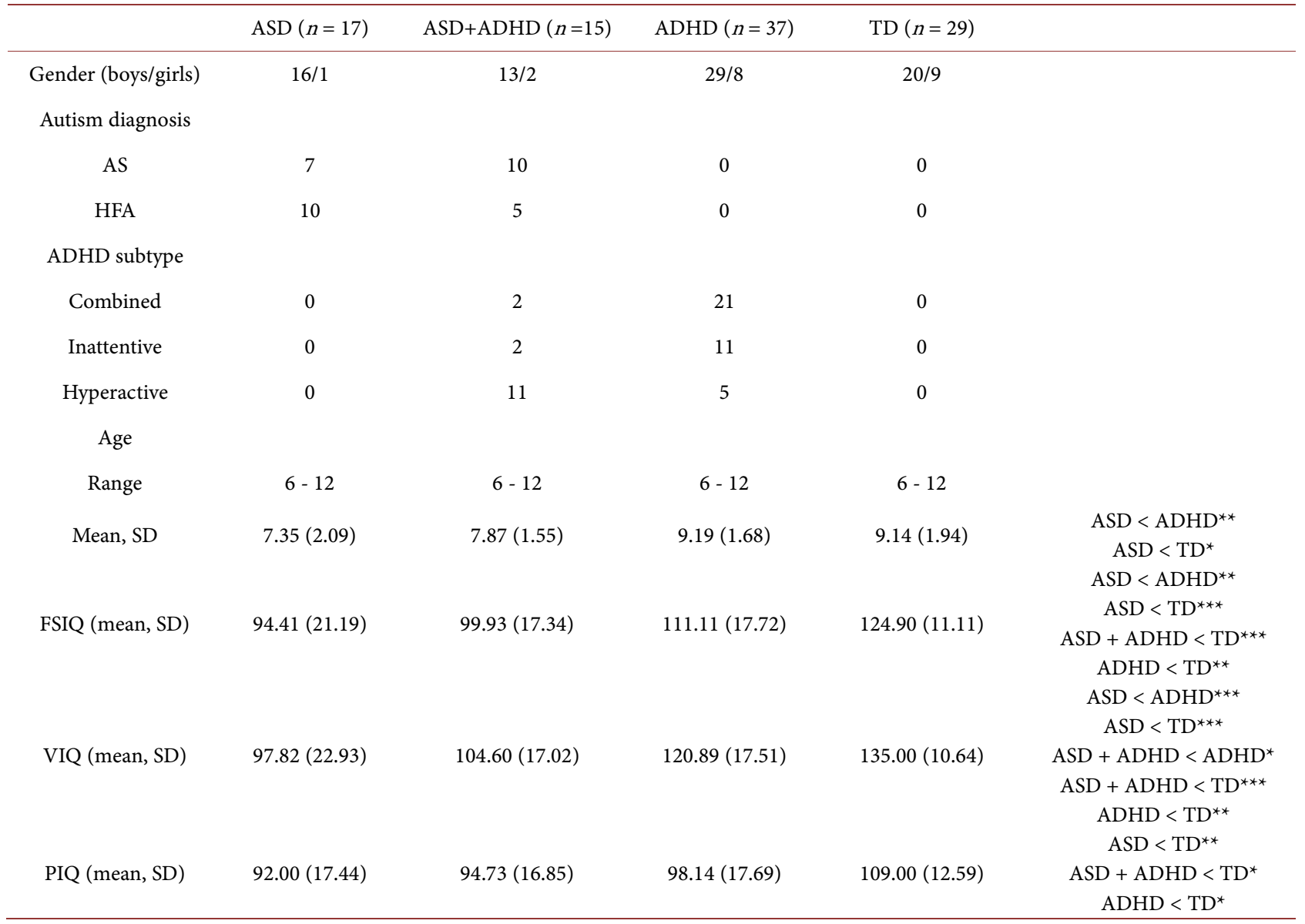

One-way analysis of variance (ANOVA) with Post hoc group comparisons for age and IQ differences, ${ }^{*} p<0.05,{ }^{* *} p<0.01,{ }^{* * *} p<0.001$. ASD $=$ autism spectrum disorder; $\mathrm{ASD}+\mathrm{ADHD}=$ comorbid $\mathrm{ASD}$ and $\mathrm{ADHD} ; \mathrm{ADHD}=$ attention deficit hyperactivity disorder; $\mathrm{TD}=$ typically developing children; $\mathrm{AS}=$ Asperger Syndrome; HFA = high functioning autism; FSIQ = Full scale IQ; VIQ = Verbal IQ; PIQ = Performance IQ.

epilepsy, and fragile-X), a full scale of IQ (FSIQ) lower than 70 measured with the Arabic version of Wechsler Intelligence Scale for Children-Third Revision (WISC-III; Kamel \& Ismail, 1999; Wechsler, 1991), and ADHD medication (i.e., psychostimulants and Atomoxetine) were used as exclusion criteria. However, one child, who started Atomoxetine therapy one week prior to the assessment was included in the study, as there is a four- to six-week window period before the therapeutic effect of this medication starts (Taylor, Paton, \& Shitij, 2012).

The study was approved by the ethical committee of the Rights of Human Subjects in Scientific Research in General Secretariat of Mental Health in Cairo, Egypt. The procedure was fully explained to the participants' parents and informed consents were obtained from all parents before study enrolment.

\subsection{Measures}

A developmental neuropsychological assessment NEPSY for 3- to 12-year-old children was employed to investigate the neurocognitive development in five neuropsychological domains (i.e., Attention and Executive Functions, Language, Sensorimotor Functions, Visuospatial Processing, and Memory and Learning) 
and each domain comprises of several subtests (Korkman, Kirk, \& Kemp, 1997; Korkman, Kirk, \& Kemp, 1998). We addressed the first edition of NEPSY, as NEPSY-II was not available during the time of data collection. The NEPSY is adapted and standardized from its original Finnish version (Korkman et al., 1997) into a United States (US) version (Korkman, et al., 1998). The original Finnish NEPSY subtests of Object Recognition, Object Memory, and Comprehension of Sentence Structure do not exist in US NEPSY version. The psychometric properties of NEPSY are satisfactory (Korkman, 2000). All NEPSY subtests have verbal instructions and most of them include initial practice trials to reduce the novelty effect and to ensure that the participant understands the task.

For the purpose of this study, the authors translated the US version of NEPSY into Arabic. In addition, the NEPSY subtest of Comprehension of Sentence Structure was translated from the Finnish version of NEPSY into Arabic. A process of repeated translation and back-translation took place until the congruent Arabic version was achieved. Arabic versions of Comprehension of Sentence Structure, Comprehension of Instruction, and Sentence Repetition subtests have the same content and nearly the same number of words as the original US/Finnish versions. In Narrative Memory subtest, we made certain that the Arabic version of the story has the same sequence of events, same number of sentences, and same total number of words as the US NEPSY version. Appropriate Arabic list of words has been chosen carefully for Phonological Processing subtest to allow omitting and substituting syllables producing new real words. Arabic tongue twisters have been used for Oromotor Sequences subtest. Regarding the selecting of suitable Arabic letters for the phonemic part of Verbal Fluency subtest, letters S (seen) and F (faa) were found to be appropriate regarding the frequency of the words that start with these letters and because these letters are not commonly attached to the words as prefixes. List Learning and Memory subtest was also translated into Arabic. Eight Arabic names were elected for Memory of Names subtest. In order to implement Auditory Attention and Response Set subtest, a new audiotape was recorded in Arabic language, on which words and colors are recorded in the same order and at the same speed as on the English audiotape. In repetition of Nonsense Words subtest, the original US NEPSY audio recording was used.

Full neuropsychological assessment using the NEPSY was undertaken with all participants, by the same examiner in a quiet room during two sessions, each lasting 1 - 1.5 hours. Short descriptions of the employed NEPSY subtests in each domain are listed below:

Attention and Executive Functions includes six subtests (Tower, Auditory Attention and Response Set, Visual Attention, Statue, Design Fluency, and Knock and Tap), that which measure the ability to shift and maintain selective attention, motor persistence and inhibition, non-verbal fluency and self-regulation.

Language domain includes seven subtests (Phonological Processing, Speeded Naming, Comprehension of Instructions, Repetition of Nonsense Words, Verbal Fluency, Oromotor Sequences, and Comprehension of Sentence Structure), that evaluate phonemic awareness, the ability of producing and recalling words ra- 
pidly, ability to understand and respond quickly to verbal instructions, ability to understand grammar, ability to encode and decode by repeating a pattern of nonsense words, ability to produce words and oromotor coordination.

Visuospatial Processing includes five subtests (Design Copying, Arrows, Block Construction, Route Finding, and Visual Recognition), that measure the ability to copy two dimensional shapes, visuomotor integration, line orientation, the ability to make three-dimensional constructions, the visual-spatial relation and directionality, visual recognition and perception.

Sensorimotor Functions includes five subtests (Fingertip Tapping, Imitating Hand Positions, Visuomotor Precision, Manual Motor Sequences, and Finger Discrimination), that assess the ability to finger dexterity, ideomotor praxity, visuomotor coordination, manual motor coordination, and ability to identify fingers using tactile information without the aid of vision.

Memory and Learning includes six subtests (Memory for Faces, Memory for Names, Narrative Memory, Sentence Repetition, List Learning, and Visual Memory), to assess the visual short-term memory, visuoverbal association memory, auditory working memory, and verbal learning.

\subsection{Statistical Analysis}

The statistical analyses were carried out using the IBM SPSS statistical software program, version 22.0. Since there are no available standardized scores for Arabic speaking children, we utilized the NEPSY total raw scores controlling for age, instead of age normed standard scores. Higher raw scores indicate better performance in all NEPSY subtests except for Fingertip Tapping subtest, in which the total score is the time taken to accomplish the task with a maximum total time of 300 seconds. In order to facilitate the comparisons between NEPSY subtests, participants' raw scores in Fingertip Tapping subtest were subtracted from the maximum score of 300 so that the higher score would indicate better performance also on that subtest. Furthermore, to examine the differences between groups on the five NEPSY domains (Attention and Executive Function, Language, Visuospatial Processing, Sensorimotor Function, and Memory and Learning) and assuming that the subtests included in each NEPSY domain are assessing the same neuropsychological function (Korkman et al., 1998), we formed a new set of Domain Scores by summing the raw scores of the subtests included in each domain (e.g. Domain Score of Attention and Executive Function is the sum of the raw scores of Tower, Auditory Attention and Response Set, Visual Attention, Statue, Design Fluency, and Knock \& Tap subtests).

There were significant age and IQ differences between the groups (Table 1). The relatively small sample size restrained us from using multiple covariates, thus we chose to control for age in our further analysis. To examine the differences in mean scores in NEPSY Domain Scores and NEPSY subtests' raw scores, we conducted multivariate analyses of covariance (MANCOVA) test with the groups (i.e. ASD, ADHD, ASD + ADHD, and TD groups) as a fixed factor and either NEPSY Domain scores or NEPSY raw scores as dependent variables, controlling for age (Table 2). We found a significant main effect of group ( $F(15$, 
Table 2. Means and standard errors of raw scores for NEPSY domains and subtests by MANCOVA controlling for age.

\begin{tabular}{|c|c|c|c|c|}
\hline & $\begin{array}{c}\text { ASD } \\
M(S E)\end{array}$ & $\begin{array}{c}\text { ASD+ADHD } \\
M(S E)\end{array}$ & $\begin{array}{l}\text { ADHD } \\
M(S E)\end{array}$ & $\begin{array}{c}\text { TD } \\
M(S E)\end{array}$ \\
\hline Attention and Executive Functions & $64.59(15.03)$ & $69.13(19.35)$ & $147.46(8.00)$ & $177.35(6.24)$ \\
\hline Tower & $11.09(0.84)$ & $11.21(0.87)$ & $14.00(0.56)$ & $15.17(0.62)$ \\
\hline Auditory Attention \& Response Set0 & $13.14(8.44)$ & $9.79(8.72)$ & $54.23(5.65)$ & $70.62(6.24)$ \\
\hline -Auditory Attention & $13.86(4.60)$ & $12.76(4.75)$ & $35.24(3.08)$ & $40.68(3.40)$ \\
\hline -Response Set & $0.71(4.54)$ & $2.99(4.69)$ & $18.99(3.03)$ & $29.94(3.35)$ \\
\hline Visual Attention & $7.28(1.29)$ & $8.80(1.33)$ & $11.99(0.86)$ & $14.73(0.95)$ \\
\hline Statue & $13.94(1.61)$ & $16.92(1.66)$ & $22.83(1.07)$ & $23.72(1.19)$ \\
\hline Design Fluency & $10.80(1.63)$ & $10.34(1.68)$ & $17.76(1.09)$ & $20.71(1.20)$ \\
\hline Knock \& Tap & $20.26(1.47)$ & $19.31(1.51)$ & $25.35(0.98)$ & $27.99(1.08)$ \\
\hline -Knock \& Tap-part 1 & $11.66(0.68)$ & $10.75(0.70)$ & $13.03(0.45)$ & $14.31(0.50)$ \\
\hline -Knock \& Tap-part 2 & $8.60(0.91)$ & $8.56(0.94)$ & $12.32(0.60)$ & $13.68(0.67)$ \\
\hline Language & $117.35(13.52)$ & $137.33(10.91)$ & $185.97(7.51)$ & $217.45(6.95)$ \\
\hline Phonological Processing & $20.17(1.65)$ & $20.67(1.71)$ & $25.60(1.10)$ & $28.89(1.22)$ \\
\hline Speeded Naming & $11.12(2.79)$ & $11.16(2.89)$ & $20.11(1.87)$ & $28.93(2.07)$ \\
\hline Comprehension of Instructions & $15.70(0.79)$ & $17.36(0.81)$ & $20.50(0.52)$ & $23.42(0.58)$ \\
\hline Repetition of Nonsense Words & $14.14(2.21)$ & $16.61(2.28)$ & $18.87(1.47)$ & $20.20(1.63)$ \\
\hline Verbal Fluency & $19.19(2.69)$ & $25.44(2.78)$ & $33.88(1.80)$ & $38.38(1.99)$ \\
\hline Verbal Fluency-Semantic & $14.82(2.11)$ & $18.67(2.17)$ & $26.78(1.40)$ & $29.67(1.55)$ \\
\hline Verbal Fluency-Phonemic & $4.24(0.95)$ & $6.68(0.98)$ & $7.16(0.63)$ & $9.09(0.70)$ \\
\hline Oromotor Sequences & $37.83(2.79)$ & $40.80(2.88)$ & $46.72(1.86)$ & $55.15(2.06)$ \\
\hline Comprehension of Sentence Structure & $13.53(0.64)$ & $13.98(0.66)$ & $16.15(0.43)$ & $17.19(0.47)$ \\
\hline Visuospatial Processing & $81.06(5.67)$ & $76.53(6.15)$ & $101.68(4.06)$ & $111.38(3.35)$ \\
\hline Design Copying & $43.30(2.80)$ & $40.24(2.90)$ & $49.16(1.87)$ & $51.76(2.07)$ \\
\hline Arrows & $14.06(1.36)$ & $14.21(1.41)$ & $17.51(0.91)$ & $21.55(1.01)$ \\
\hline Block Construction & $9.64(0.69)$ & $8.78(0.72)$ & $10.49(0.46)$ & $11.93(0.51)$ \\
\hline Route Finding & $5.06(0.62)$ & $4.59(0.64)$ & $5.80(0.42)$ & $6.34(0.46)$ \\
\hline Visual Recognition & $16.42(1.18)$ & $13.24(1.22)$ & $16.26(0.79)$ & $17.05(0.87)$ \\
\hline Sensorimotor Functions & $261.82(21.11)$ & $262.67(27.84)$ & $343.11(8.17)$ & $368.41(5.12)$ \\
\hline Fingertip tapping & $176.81(11.78)$ & $175.70(12.17)$ & $222.915(7.88)$ & $235.19(8.71)$ \\
\hline Imitating Hand Positions & $16.58(1.06)$ & $16.33(1.09)$ & $20.71(0.71)$ & $21.15(0.78)$ \\
\hline Imitating Hand Positions-Preferred Hand & $8.40(0.54)$ & $8.24(0.56)$ & $10.40(0.36)$ & $10.74(0.40)$ \\
\hline Imitating Hand Positions-Non-preferred Hand & $8.17(0.58)$ & $8.09(0.60)$ & $10.30(0.38)$ & $10.40(0.43)$ \\
\hline Visuomotor Precision & $12.03(1.88)$ & $12.89(1.95)$ & $20.23(1.26)$ & $24.22(1.39)$ \\
\hline Manual Motor Sequences & $41.97(2.60)$ & $36.61(2.68)$ & $45.99(1.74)$ & $51.64(1.92)$ \\
\hline Finger Discrimination-Preferred Hand & $12.46(0.86)$ & $13.58(0.89)$ & $15.16(0.57)$ & $16.55(0.63)$ \\
\hline Finger Discrimination-Non-preferred Hand & $12.13(0.90)$ & $13.70(0.93)$ & $15.21(0.60)$ & $15.91(0.66)$ \\
\hline
\end{tabular}




\begin{tabular}{ccccc}
\hline Memory and Learning & $98.06(7.48)$ & $106.13(8.64)$ & $150.70(5.55)$ & $170.66(4.65)$ \\
Memory for Faces & $19.48(1.14)$ & $22.35(1.18)$ & $26.65(0.76)$ & $26.99(0.84)$ \\
Immediate Memory for Faces & $9.38(0.58)$ & $11.62(0.60)$ & $13.21(0.39)$ & $13.67(0.43)$ \\
Delayed Memory for Faces & $10.06(0.72)$ & $10.71(0.75)$ & $13.17(0.48)$ & $13.33(0.53)$ \\
Memory for Names & $21.91(1.61)$ & $16.21(1.67)$ & $20.77(1.08)$ & $23.29(1.19)$ \\
Immediate Memory for Names & $15.86(1.19)$ & $11.90(1.23)$ & $15.11(0.79)$ & $16.77(0.88)$ \\
Delayed Memory for Names & $6.21(0.59)$ & $4.96(0.61)$ & $5.65(0.40)$ & $6.52(0.44)$ \\
Narrative Memory & $9.40(1.68)$ & $13.11(1.74)$ & $24.86(1.12)$ & $27.56(1.24)$ \\
Narrative Memory-Free Recall & $7.07(1.97)$ & $9.87(2.04)$ & $21.05(1.32)$ & $24.60(1.46)$ \\
Narrative Memory-Cued Recall & $2.32(0.66)$ & $3.23(0.68)$ & $3.80(0.44)$ & $2.95(0.49)$ \\
Sentence Repetition & $12.64(1.24)$ & $16.01(1.28)$ & $19.94(0.83)$ & $24.06(0.91)$ \\
List Learning & $35.80(3.44)$ & $34.82(3.56)$ & $46.40(2.30)$ & $55.94(2.54)$ \\
Immediate List Memory & $30.96(2.90)$ & $29.04(2.99)$ & $36.71(1.94)$ & $44.97(2.14)$ \\
Delayed List Memory & $6.25(1.29)$ & $5.99(1.33)$ & $9.53(0.86)$ & $8.92(0.37)$ \\
Visual Memory & $8.01(0.55)$ & $9.19(0.57)$ & $9.43(0.41)$ \\
\hline
\end{tabular}

Higher scores reflect better performance. ASD = autism spectrum disorder; ASD + ADHD = comorbid ASD and ADHD; ADHD = attention deficit hyperactivity disorder; $\mathrm{TD}=$ typically developing children.

246) $=4.76, p<.001$, Wilks' Lambda $\left.=.495, \eta_{p}^{2}=.209\right)$ and age $(F(5,89)=$ $6.09, p<.001$, Wilks' Lambda $\left.=.745, \eta_{p}^{2}=.255\right)$ on NEPSY Domain scores. Further we also found a significant main effect of group $(F(129,153)=2.24, p$ $<.001$, Wilks' Lambda $\left.=.042, \eta_{p}^{2}=.652\right)$ and age $(F(43,51)=2.57, p<.01$, Wilks' Lambda $\left.=.315, \eta_{p}^{2}=.685\right)$ in NEPSY raw scores.

In the follow-up between the group analyses we focused on six contrasts controlling for age. First, we compared each diagnostic group with the TD group. Second, we compared the diagnostic groups with each other. Effect size was evaluated by using the Eta-squared $\left(\eta_{p}^{2}\right)$ statistic. A significant threshold of $\leq$ 0.001 was set for NEPSY subtests' raw scores and of $\leq 0.01$ for NEPSY Domain Scores to control false discoveries in multiple comparisons.

\section{Results}

Between-group comparisons revealed that TD children scored highest on all NEPSY domains, followed by children with ADHD, then children with ASD + ADHD and ASD. Children with ADHD showed significantly poorer performance than TD children on NEPSY domains of Attention and Executive Function, Language, and Memory. Also, both ASD and ASD + ADHD groups scored significantly lower than ADHD group on all NEPSY domains aside from Visuospatial Processing. Table 2 \& Table 3 compares the means of NEPSY domains and neuropsychological performance in TD children, children with ADHD, children with ASD + ADHD and ASD, respectively.

ASD group compared with TD group. ASD group performed significantly 
Table 3. Neuropsychological performance on NEPSY by MANCOVA controlling for age

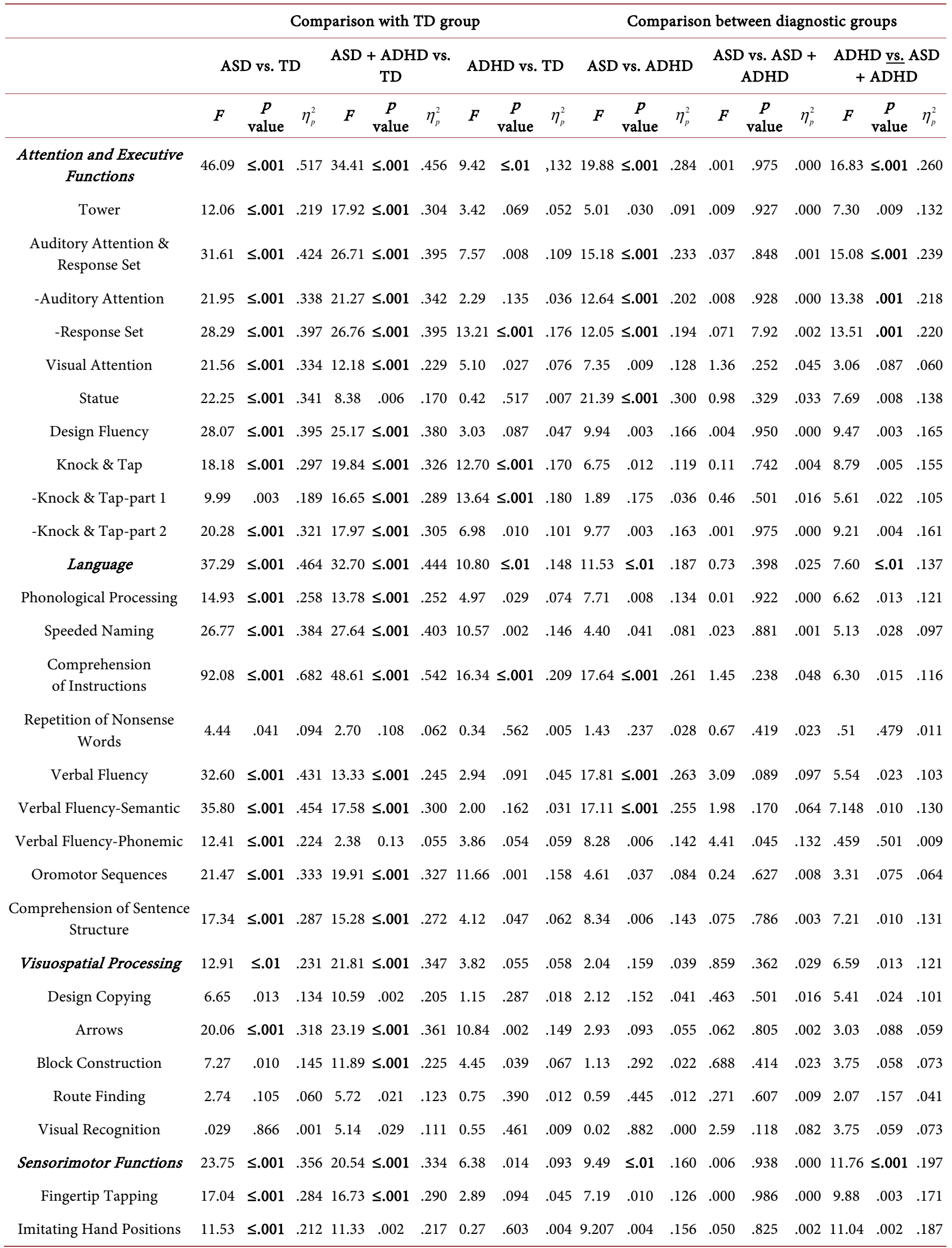




\section{Continued}

Imitating Hand PositionsPreferred Hand

Imitating Hand PositionsNon-preferred Hand

Visuomotor Precision

Manual Motor Sequences

Finger DiscriminationPreferred Hand

Finger DiscriminationNon-preferred Hand

Memory and Learning

Memory for Faces

Immediate Memory for Faces

Delayed Memory for Faces Memory for Names

Immediate Memory for Names

Delayed Memory for Names

Narrative Memory

Sentence Repetition

List Learning

Immediate List Memory

Delayed List Memory

Visual Memory

Immediate Memory for Names

Delayed Memory for Names

Narrative Memory

Sentence Repetition

List Learning

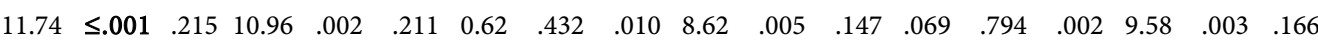

$\begin{array}{llllllllllllllllll}6.97 & .011 & .140 & 9.78 & .003 & .193 & 0.046 & .832 & .001 & 7.44 & .009 & .130 & .025 & .874 & .001 & 11.21 & .002 & .189\end{array}$

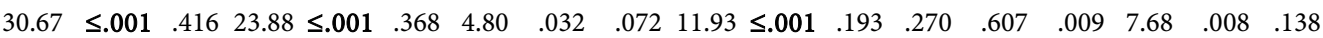

$\begin{array}{llllllllllllllllll}7.68 & .008 & .152 & 24.20 & \leq .001 & .371 & 9.22 & .003 & .130 & 0.57 & .453 & .011 & 1.15 & .291 & .038 & 8.32 & .006 & .148\end{array}$

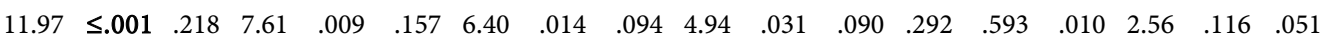

$\begin{array}{llllllllllllllllll}8.99 & .004 & .173 & 4.58 & .038 & .101 & 1.44 & .235 & .023 & 5.38 & .024 & .097 & .560 & .460 & .019 & 2.52 & .119 & .050\end{array}$

$\begin{array}{llllllllllllllllll}61.65 & \leq .001 & .589 & 42.43 & \leq .001 & .509 & 8.39 & \leq .01 & .119 & 16.09 & \leq .001 & .244 & .202 & .657 & .007 & 12.33 & \leq .01 & .204\end{array}$

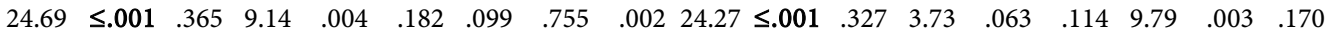

$\begin{array}{llllllllllllllllll}34.62 & \leq .001 & .446 & 9.06 & .004 & .181 & .669 & .416 & .011 & 22.83 & \leq .001 & .314 & 7.47 & .011 & .205 & 4.64 & .036 & .088\end{array}$

$\begin{array}{llllllllllllllllll}11.36 & .002 & .209 & 6.45 & .015 & .136 & .054 & .817 & .001 & 12.75 & .001 & .203 & .536 & .470 & .018 & 8.34 & .006 & .148\end{array}$

$\begin{array}{llllllllllllllllll}0.36 & .551 & .008 & 12.28 & \leq .001 & .231 & 2.52 & .117 & .039 & 0.259 & .613 & .005 & 5.88 & .022 & .169 & 4.33 & .043 & .083\end{array}$

$\begin{array}{llllllllllllllllll}0.23 & .631 & .005 & 9.51 & .004 & .188 & 1.93 & .170 & .030 & 0.07 & .792 & .001 & 5.61 & .025 & .162 & 4.16 & .047 & .080\end{array}$

$\begin{array}{llllllllllllllllll}0.33 & .567 & .008 & 3.70 & .061 & .083 & 3.49 & .066 & .053 & 1.62 & .209 & .031 & 1.28 & .266 & .042 & .516 & .476 & .011\end{array}$

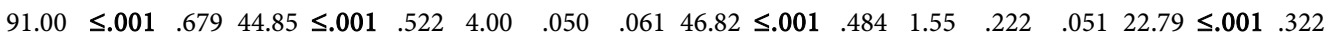

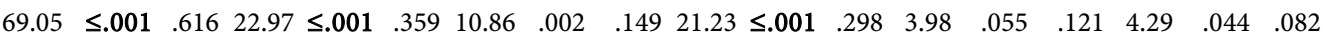

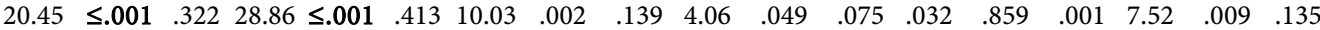

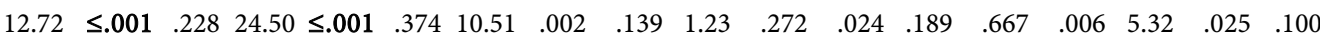
$\begin{array}{llllllllllllllllll}16.60 & \leq .001 & .279 & 30.51 & \leq .001 & .427 & 0.854 & .359 & .014 & 2.38 & .129 & .046 & .078 & .782 & .003 & 3.52 & .067 & .060\end{array}$ $\begin{array}{llllllllllllllllll}3.63 & .063 & .078 & 0.01 & .911 & .000 & 0.88 & .352 & .014 & 2.34 & .132 & .045 & 2.52 & .123 & .080 & .166 & .685 & .003\end{array}$ $\begin{array}{llllllllllllllllll}0.23 & .631 & .005 & 9.51 & .004 & .188 & 1.93 & .170 & .030 & 0.07 & .792 & .001 & 5.61 & .025 & .162 & 4.16 & .047 & .080\end{array}$ $\begin{array}{llllllllllllllllll}0.33 & .567 & .008 & 3.70 & .061 & .083 & 3.49 & .066 & .053 & 1.62 & .209 & .031 & 1.28 & .266 & .042 & .516 & .476 & .011\end{array}$

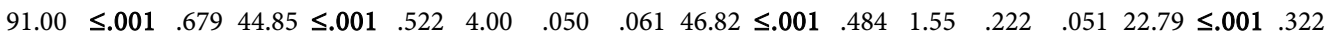

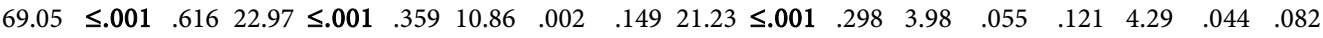
$\begin{array}{llllllllllllllllll}20.45 & \leq .001 & .322 & 28.86 & \leq .001 & .413 & 10.03 & .002 & .139 & 4.06 & .049 & .075 & .032 & .859 & .001 & 7.52 & .009 & .135\end{array}$

Raw scores were used in MANCOVA analysis. Significant differences appear in boldface. $p$ values for controlling multiple comparison effect are $p<0.01$ for NEPSY domains and $p \leq 0.001$ for NEPSY subtests. ASD = autism spectrum disorder; ASD + ADHD = comorbid ASD and ADHD; ADHD = attention deficit hyperactivity disorder; $\mathrm{TD}=$ typically developing children .

lower than TD group in all NEPSY Domain Scores (Attention and Executive Function, Language, Visuospatial Processing, Sensorimotor, and Memory and Learning). We also found a trend of lower performance of ASD group in comparison to TD group in all NEPSY subtests. There were statistically significant differences between children with ASD and TD children in all subtests except Repetition of Nonsense Words, Design Copying, Block Construction, Route Finding, Visual Recognition, Imitating Hand Positions (non-preferred hand), Manual Motor Sequences, Finger Discrimination (non-preferred hand), Delayed 
Memory for Faces, Memory for Names and Visual Memory (Table $2 \&$ Table 3).

ASD + ADHD group compared with TD group. ASD + ADHD group scored significantly lower than TD group in all NEPSY Domain Scores. There was also a trend of lower performance of ASD + ADHD group in comparison to TD group in all NEPSY subtests. Statistically significant differences were found in all subtests except on Statue, Repetition of Nonsense Words, Phonemic Verbal Fluency, Design Copying, Route Finding, Visual Recognition, Imitating Hand Positions, Finger Discrimination, Memory for Faces, and Visual Memory (Table 2 \& Table 3).

ADHD group compared with TD group. ADHD group scored significantly lower than TD group in NEPSY Domain Scores of Attention and Executive Function, Language, and Memory and Learning. On Attention and Executive Functions domain ADHD group scored significantly lower than TD group in Response Set, Knock \& Tap subtest, and on Language domain in Comprehension of Instruction subtest (Table $2 \&$ Table 3 ).

ASD group compared with ADHD group. ASD group scored significantly lower than ADHD group in all NEPSY Domain Scores except Visuospatial Processing. ASD group scored significantly lower than ADHD group in the subtests of Auditory Attention and Response Set, Statue, Comprehension of Instruction, Verbal Fluency, Visuomotor Precision, Memory for Faces, Narrative Memory, and Sentence Repetition (Table $2 \&$ Table 3).

ASD group compared with ASD + ADHD group. There were no significant differences found between these two groups (Table $2 \&$ Table 3 ).

ADHD group compared with ASD + ADHD group. ADHD group scored significantly higher than ASD + ADHD group in all NEPSY Domain Scores except Visuospatial Processing. Specifically, ADHD group scored significantly higher than ASD + ADHD group in the subtests of Auditory Attention and Response Set, and Narrative Memory (Table 2 \& Table 3).

\section{Discussion}

We compared the neuropsychological profiles of attention and executive function, language, visuospatial processing, sensorimotor function, and memory in Egyptian children with ASD, ASD + ADHD, ADHD, and TD employing a single neuropsychological battery. Whilst Egyptian children with ASD and ASD + ADHD demonstrated generalized impairment on neuropsychological performance, compared to TD children, we did not find specific differences between children with ASD and children with ASD + ADHD. Our results, however, suggest that compared to TD children, some neuropsychological abilities, such as planning, hand motor coordination, and verbal working memory, may worsen, in children with ASD + ADHD. In contrast, compared to TD children, problems in some neuropsychological abilities, such as verbal fluency, hand praxis, finger gnosis, and face memory may be mitigated in children having both ASD and ADHD. 


\subsection{Attention and Executive Function Domain}

Attention and executive function is a broad term and it refers to higher order cognitive skills, which are important in order to maintain goal-directed performance in new or complex situations (Hunter, Edidin, \& Hinkle, 2012). Similar to previous neuropsychological studies of children with ASD (Ambery, Russell, Perry, Morris, \& Murphy, 2006; Barron-Linnankoski et al., 2015; Joseph, McGrath, \& Tager-Flusberg, 2005; Korkman et al., 1998; Mahone, Powell, Loftis, Goldberg, Denckla, \& Mostofsky, 2006; Narzisi et al., 2013; Ozonoff et al., 2004; Verté, Geurts, Roeyers, Oosterlaan, \& Sergeant, 2006), Egyptian children with ASD and ASD + ADHD performed significantly poorer than TD children in tasks requiring selective auditory attention, maintaining the auditory attention and shifting the attention between different auditory demands as well as motor persistence and inhibition. Additionally, slower non-verbal fluency and visual scanning as well as poorer non-verbal problem solving skills of children with ASD and ASD + ADHD compared to the TD children might be explained by the nature of NEPSY tasks: these tasks depend mainly on strategic generation of designs and/or plans that are not previously stored in memory and therefore require flexible, non-routinized imaginativeness. There have been mixed evidence of design fluency, visual attention, and non-verbal problem solving with some previous studies reaching to similar results as our study (Hooper et al., 2006; Joseph et al., 2005; Losh et al., 2009; Narizi et al., 2013; Planche and Lemonnier, 2012) and others contradicting it (Barron-Linnankoski et al., 2015; Kleinhams, Akshoomoff, \& Delis, 2005; Losh et al., 2009; Planche and Lemonnier, 2012; Turner, 1999), further research is warranted in this area. The generalized and profound impairment of attention and executive function in children with ASD and ASD + ADHD can be attributed to perseverative characteristics of ASD (Corbett, Constantine, Hendren, Rocke, \& Ozonoff, 2009; Happé, Booth, Charlton, \& Hughes, 2006) and/or failure to use the language for self-regulation. Weakness in verbal working memory (i.e., verbal self-reminding) can make children with ASD susceptible to errors in executive tasks (Joseph, McGrath, \& Tager-Flusberg, 2005; Liss et al., 2001).

In addition to the fact that children with ASD and ASD + ADHD performed significantly less accurately than TD children, they also scored lower than children with ADHD in tasks requiring auditory attention, motor inhibition, and changing response style. It is possible that ASD symptoms in children with or without ADHD worsen both the impulsivity control and the motor and cognitive flexibility. In consistence with earlier findings, Egyptian children with ADHD scored lower than TD children on Attention and Executive Function domain, specifically in tasks requiring motor inhibition, which is the core symptom of impulsivity in ADHD (Happé et al., 2006; Sergeant, Geurts, \& Oosterlaan, 2002; Tsal, Shalev, \& Mevorach, 2005; Willcutt, Doyle, Nigg, Faraone, \& Pennington, 2005; Youngwirth, Harvey, Gates, Hashim, \& Friedman-Weieneth, 2007). Executive function impairments in children with ADHD might also be due to deficit in inhibitory control (Buhler et al., 2011; Happé, Booth, Charlton, 
\& Hughes, 2006).

\subsection{Language Domain}

Our results demonstrated that children with ADHD did not show as wideranging language difficulties as we expected based on earlier studies (e.g. Kim \& Kaiser, 2000; Purvis \& Tannock, 1997). However, this study confirmed earlier findings (e.g., Barini \& Hage, 2015; Purvis \& Tannock, 1997) that children with ADHD have verbal comprehension difficulties. It is of note that we used Comprehension of Instructions subtest, which demands the ability to receive, process, and execute instructions of increasing syntactic complexity, which may have further increased the working memory load. Previously Barini and Hage (2015) suggested that verbal comprehension difficulties in ADHD are connected with weak verbal working memory. However, in our study, children with ADHD did not perform significantly weaker than TD children in verbal memory tasks. Others suggested the reason for language difficulties in ADHD is impulsivity (Geurts \& Embrechts, 2008), which might be a factor behind the weak verbal comprehension abilities of children with ADHD found in our study.

Our finding of poorer performance in children with ASD compared to TD children on Language domain is consistent with previous studies using NEPSY (Hooper et al., 2006; Korkman et al., 2007; Narzisi et al., 2013). Also, our results concur with other studies on language deficits in children with ASD and expanded the findings as affecting also children with ASD + ADHD. In line with earlier studies that compared children with ASD and ASD + ADHD to TD children (Ambery et al., 2006; Barron-Linnankoski et al., 2015; Bramham et al., 2009; Geurts et al., 2004; Tager-Flusberg, 2004; Narzisi et al., 2013; Rumsey \& Hamburger 1988, 1990; Saalasti et al., 2008; Turner 1999; Verte et al., 2006), both groups had wide-ranging language difficulties in generating words of semantic category, processing and responding to verbal instruction of increasing syntactic complexity, accessing and producing familiar words, understanding the grammar of sentences with increasing complexity, and in rhythmic oromotor coordination. Similarly, our ASD and ASD + ADHD samples demonstrated deficits in identifying words from segments and forming an auditory gestalt (Tager-Flusberg, 2004; Narzisi et al., 2013) and deficits in phonemic fluency (Tager-Flusberg, 2004; Schmidt, Kopelioff, Winterrowd, Pennington, Hepburn, \& Rojas, 2008). However, in contrast, results from a study by Barron-Linnankoski and colleagues (2015) found intact comprehension of instructions in their ASD sample, which might be attributed to IQ differences when compared to our sample. In our sample, children with ASD and ASD + ADHD showed intact ability of encoding and decoding a sound pattern (repetition of nonsense words). Whitehouse, Barry and Bishop (2008) concluded that impairment in repetition of nonsense words is seen only in some children with ASD and depends on the ASD symptom severity and impairments in structural language. This conclusion provides a possible explanation of why this ability was spared in our sample given that we only included high-functioning children with ASD in our 
study. Nevertheless, our finding should be interpreted with caution, as we used the original English audiotape of nonsense words of NEPSY instead of inventing an Arabic one. We found children with ASD or ASD + ADHD to have difficulties in many aspects of language, such as semantics and syntax that undoubtedly have an effect on their linguistic competence. In addition to impaired social and communication skills (APA, 2013), language difficulties may further affect children's communication with peers and their school performance.

\subsection{Visuospatial Processing Domain}

In line with the earlier ASD studies (Hooper, Poon, Marcus, \& Fine, 2006; Korkman, Kirk, \& Kemp, 2007; Narzisi et al., 2013), that used NEPSY, our sample of children with ASD and ASD + ADHD faired worse than TD children in their ability to judge line orientation. However, there is another study that employed another measure different from NEPSY showing contradicting results (Planche \& Lemonnier, 2012). Thus, it is possible that the demands of shifting attention in the line orientation subtest of NEPSY (i.e., the variability of location and size of the lines), along with occasional slippages in visual attention and scanning, may negatively influence subjects' performance.

Further, our results showed that children with ASD and ASD + ADHD might have intact object recognition and perception, and understanding of visuospatial relationships and directionality, in line with previous studies (Kuusikko-Gauffin et al., 2011; Losh et al., 2009). Also, our results regarding impairment in abilities of copying two-dimensional geometric figures in ASD are consistent with another study (Narzisi et al., 2013). The ability to reproduce three-dimensional block constructions from models and pictures was found to be intact in our sample of children with ASD but not in ASD + ADHD relative to TD children. It is possible that the ADHD symptoms might hinder the strategic planning capability of children with ASD. Relatively intact visuospatial processing may thus be one of the areas of strength in children with ASD and it could be employed in interventions, such as using pictorial information instead of lexical information.

\subsection{Sensorimotor Domain}

Similar to Youngwirth and colleagues (2007), we did not find any difference between children with ADHD and TD children in sensorimotor abilities. For children with ASD and ASD + ADHD, we found them to perform poorer than TD children particularly in fingertip tapping and visuomotor tasks. This replicates the finding of Ham, Corley, Rajendra, Carletta, \& Swanson (2008) and Hooper, Poon, Marcus, \& Fine, (2006) but was inconsistent with the results of another study (Narzisi et al., 2013). Impairment in Fingertip Tapping subtest might be related to deficits in executive function, set shifting, and lack of cognitive flexibility in ASD. The visuomotor subtest examined both speed and accuracy, which might have contributed to a slower and/or less accurate performance of children with ASD. Additionally, children with ASD + ADHD encountered difficulties in imitating series of rhythmic movements but this was not the case 
in children with pure ASD and could be related to impaired executive function in ADHD.

\subsection{Memory and Learning Domain}

Memory for faces was significantly impaired in our ASD sample, confirming the findings of previous research (Barron-Linnankoski et al., 2015; Blair, Frith, Smith, Abell, \& Cipolotti, 2002; Garcia, 2001; Hooper, Poon, Marcus, \& Fine, 2006; Narzisi et al., 2013; O’shea, Fein, Cillesen, Klin, \& Schltz, 2005; Williams, Goldstein, \& Minshew, 2006a). Impairment of recalling names was only found in children with ASD + ADHD but not in children with pure ASD. This may be the result of the additive effect of ADHD symptoms. Our findings are also consistent with previous studies (Barron-Linnankoski et al., 2015; Blair et al 2002; Garcia, 2001; Hooper, Poon, Marcus, \& Fine, 2006; Korkman, Kirk, \& Kemp, 1998; Minshew and Goldstein 2001; Narzisi et al., 2013; O'shea et al., 2005; Williams, Goldstein, \& Minshew, 2006a; Williams, Goldstein, \& Minshew, 2006b). Deficits in verbal working memory, difficulties in developing strategies for free recall of information, and difficulties in organizing words and resisting interference are further reasons to favor pictorial information instead of lexical in the interventions and in the teaching materials provided for children with ASD (Bowler, Matthews, \& Gardiner, 1997; Barendse et al., 2013; Narzisi et al., 2013).

\section{Conclusion}

Egyptian children with ASD, ASD + ADHD, and ADHD demonstrated generalized impairment on neuropsychological performance, which is consistent with reports from other countries. Rather unexpectedly, we did not find statistically significant differences between children with ASD and children with ASD + ADHD in neuropsychological performance. Whilst ADHD symptoms may not automatically increase the neuropsychological deficits in children with ASD, our results suggest that the presence of ADHD symptoms in children with ASD could worsen their ability to plan, hand motor coordination, and memorizing names. Nevertheless, these symptoms may mitigate the difficulties that ASD children may have in other neuropsychological areas, such as verbal fluency, hand praxis, finger gnosis, and face memory. Our findings may well impact management plans for ASD: As communication difficulty is one of the most impairing features of ASD, language skills of children should be carefully assessed when planning interventions for these patients. As such, relatively intact visuospatial processing may be one of the areas of strength in children with ASD, it could be employed in interventions, such as using pictorial information instead of lexical information.

\section{Suggestions for Future Research}

In spite of the limitations inherent to our study including the small sample size of each diagnostic group, this is the first study to compare the neuropsychological abilities of ASD, ASD + ADHD, ADHD and typical development in Middle 
Eastern children. Future studies with larger sample sizes are therefore warranted to validate the NEPSY in Middle East countries and to further compare the neuropsychological performance of children of ASD, ASD + ADHD, and ADHD.

\section{Acknowledgements}

The authors would like to thank the children and their parents for their participation in this study. We express our gratitude to the ADI-R Arabic translation team including experts from Saudi Arabia, Egypt, and Qatar. This study was supported by Alma and KA Snellman Foundation, Oulu, Finland and Thule Institute, University of Oulu, Finland.

\section{Conflict of Interest}

The authors report no conflicts of interest.

\section{References}

Ambery, F. Z., Russell, A. J., Perry, K., Morris, R., \& Murphy, D. G. (2006). Neuropsychological Functioning in Adults with Asperger Syndrome. Autism, 10, 6551-6564. https://doi.org/10.1177/1362361306068507

American Psychiatric Association (APA) (2013). Diagnostic and Statistical Manual of Mental Disorders (DSM-5, 5th ed.). Washington DC: American Psychiatric Association. https://doi.org/10.1176/appi.books.9780890425596

Ames, C. S., \& White, S. J. (2011). Brief Report: Are ADHD Traits Dissociable from the Autistic Profile? Links between Cognition and Behaviour. Journal of Autism and Developmental Disorders, 41, 357-363. https://doi.org/10.1007/s10803-010-1049-0

Barendse, E., Hendricks, M., Jansen, J., Backes, W., Hofman, P., Thoonen, G., Kessels, R., \& Aldenkamp, A. (2013). Working Memory Deficits in High Functioning Adolescents with Autism Spectrum Disorders: Neuropsychological and Neuroimaging Correlates. Journal of Neurodevelopmental Disorders, 5, 14. https://doi.org/10.1186/1866-1955-5-14

Barini, N. S., \& Hage, S. R. (2015). Vocabulary and Verbal Comprehension of Students with Attention Deficit Hyperactivity Disorder. Codas, 27, 446-451. https://doi.org/10.1590/2317-1782/20152015022

Barron-Linnankoski, S., Reinvall, O., Lahervuori, A., Voutilainen, A., Lahti-Nuuttila, P., \& Korkman, M. (2015). Neurocognitive Performance of Children with Higher Functioning Autism Spectrum Disorders on the NEPSY-II. Child Neuropsychology, 21, 55-77. https://doi.org/10.1080/09297049.2013.873781

Blair, R. J., Frith, U., Smith, N., Abell, F., \& Cipolotti, L. (2002). Fractionation of Visual Memory: Agency Detection and Its Impairment in Autism. Neuropsychologia, 40, 108-118.

Bowler, D. M., Matthews, N. J., \& Gardiner, J. M. (1997). Asperger's Syndrome and Memory: Similarity to Autism but Not Amnesia. Neuropsychologia, 35, 65-70.

Bramham, J., Ambery, F., Young, S., Morris, R., Russell, A., Xenitidis, K., Asherson, P., \& Murphy, D. (2009). Executive Functioning Differences between Adults with Attention Deficit Hyperactivity Disorder and Autistic Spectrum Disorder in Initiation, Planning and Strategy Formation. Autism, 13, 245-264.

https://doi.org/10.1177/1362361309103790 
Buhler, E., Bachmann, C., Goyert, H., Heinzel-Gutenbrunner, M., \& Kamp-Becker, I. (2011). Differential Diagnosis of Autism Spectrum Disorder and Attention Deficit Hyperactivity Disorder by Means of Inhibitory Control and "Theory of Mind". Journal of Autism and Developmental Disorders, 41, 1718-1726.

https://doi.org/10.1007/s10803-011-1205-1

Corbett, B. A., Constantine, L. J., Hendren, R., Rocke, D., \& Ozonoff, S. (2009). Examining Executive Functioning in Children with Autism Spectrum Disorder, Attention Deficit Hyperactivity Disorder and Typical Development. Psychiatry Research, 166, 210-222.

Gargaro, B. A, Rinehart, N. J., Bradshaw, J. L., Tonge, B. J., \& Sheppard, D. M. (2011). Autism and ADHD: How Far Have We Come in the Comorbidity Debate? Neuroscience and Biobehavioural Reviews, 35, 1081-1088.

Geurts, H. M., \& Embreschts, M. (2008). Language Profiles in ASD, SLI, and ADHD. Journal of Autism and Developmental Disorders, 38, 1931-1943.

https://doi.org/10.1007/s10803-008-0587-1

Geurts, H. M., Verte, S., Oosterlaan, J., Roeyers, H., \& Sergeant, J. A. (2004). How Specific Are Executive Functioning Deficits in Attention Deficit Hyperactivity Disorder and Autism? Journal of Child Psychology and Psychiatry, 45, 836-854. https://doi.org/10.1111/j.1469-7610.2004.00276.x

Goldberg, M. C., Mostowsky, S. H., Cutting, L. E., Mahone, E. M., Astor, B. C., Denckla, M. B., \& Landa, R. J. (2005). Subtle Executive Impairment in Children with Autism and Children with ADHD. Journal of Autism and Developmental Disorders, 35, 279-293. https://doi.org/10.1007/s10803-005-3291-4

Garcia, A. M. (2001). The Relationship between Source Memory and Frontal Lobe Functioning in School-Aged Children. Mansfield: University of Connecticut.

Ham, H. D., Corley, M., Rajendran, G., Carletta, J., \& Swanson, S. (2008). Brief Report: Imitation of Meaningless Gestures in Individuals with Asperger Syndrome and High-Functioning Autism. Journal of Autism and Developmental Disorders, 38, 569573. https://doi.org/10.1007/s10803-007-0417-x

Happé, F., Booth, R., Charlton, R., \& Hughes, C. (2006). Executive Function Deficits in Autism Spectrum Disorders and Attention-Deficit/Hyperactivity Disorder: Examining Profiles across Domains and Ages. Brain Cognition, 61, 25-39.

Hooper, S. R., Poon, K. K., Marcus, L., \& Fine, C. (2006). Neuropsychological Characteristics of School Age Children with High Functioning Autism: Performance on the NEPSY. Child Neuropsychology, 12, 299-305. https://doi.org/10.1080/09297040600737984

Hunter, S., Edidin, J., \& Hinkle, C. (2012). The Developmental Neuropsychology of Executive Functions. In S. Hunter, \& E. Sparrow (Eds.), Executive Function and Dysfunction Identification, Assessment and Treatment (pp. 17-36). Cambridge: Cambridge University Press. https://doi.org/10.1017/CBO9780511977954.004

Johnson, K. A., Robertson, I. H., Kelly, S. P., Silk, T. J., Barry, E., Dáibhis, A., Watchorn, A., Keavey, M., Fitzgerald, M., Gallagher, L., Gill, M., \& Bellgrove, M. A. (2007). Dissociation in Performance of Children with ADHD and High Functioning Autism on a Task of Sustained Attention. Neuropsychologia, 45, 2234-2245.

Joseph, R. M., McGrath, L. M., \& Tager-Flusberg, H. (2005). Executive Dysfunction and Its Relation to Language Ability in Verbal School Age Children with Autism. Developmental Neuropsychology, 27, 361-378. https://doi.org/10.1207/s15326942dn2703_4

Kamel, M., \& Ismail, E. (1999). Wechsler Intelligence Scale for Children (3rd ed., Arabic Version). Cairo: EL-Nahda El-Massryia.

Kaufman, J., Birmaher, B., Brent, D., Rao, U., Flynn, C., Moreci, P., Williamson, D., \& 
Ryan, N. (1997). Schedule for Affective Disorders and Schizophrenia for School Age Children-Present and Lifetime Version (k-SAD-PL): Initial Reliability and Validity Data. Journal of the American Academy of Child and Adolescent Psychiatry, 36, 980-988. https://doi.org/10.1097/00004583-199707000-00021

Kim, O. H., \& Kaiser, A. P. (2000). Language Characteristics of Children with ADHD. Communication Disorders Quarterly, 21, 154-165. https://doi.org/10.1177/152574010002100304

Kleinhams, N., Akshoomoff, N., \& Delis, D. C. (2005). Executive Functions in Autism and Asperger's Disorder: Flexibility, Fluency, and Inhibition. Developmental Neuropsychology, 27, 379-401. https://doi.org/10.1207/s15326942dn2703_5

Korkman, M., Kirk, U., \& Kemp, S. L. (2007). NEPSY-II. Clinical and Interpretative Manual. San Antonio, TX: Psychological Corporation.

Korkman, M., Kirk, U., \& Kemp, S. L. (1997). NEPSY: Lasten Neuropsykologinen Tutkimus. Helsinki: Psykologien Kustannus Oy.

Korkman, M., Kirk, U., \& Kemp, S. (1998). NEPSY: A Developmental Neuropsychological Assessment. Psych Corp. Harcourt Assessment Inc.

Korkman, M. (2000). NEPSY: Lasten neuropsykologinen tutkimus, kasikirja II, Testin tausta jasoveltaminen. Helsinki: Psykologien Kustannus Oy.

Kuusikko-Gauffin, S., Jansson-Verkasalo, E., Carter, A., Pollocl-Wurman, R., Jussila, K, Mattila, M.-L., Jukka, R., Ebeling, H., \& Moilanen, I. (2011). Face Memory and Object Recognition in Children with High Functioning Autism or Asperger Syndrome and in Their Parents. Research in Autism Spectrum Disorders, 5, 622-628.

Liss, M., Fein, D., Allen, D., Dunn, M., Feinstein, C., Morris, R., Waterhouse, L., \& Rapin, I. (2001). Executive Functioning in High-Functioning Children with Autism. Journal of Child Psychology and Psychiatry, 42, 261-270. https://doi.org/10.1111/1469-7610.00717

Lord, C., Rutter, M., \& Le Couteur, A. (1995). Autism Diagnostic Interview-Revised (3rd ed.). Los Angeles, CA: Western Psychological Services.

Lord, C., Rutter, M., Dilavore, P. C., \& Risi, S. (2000). Autism Diagnostic Observation Schedule (ADOS). Los Angeles, CA: Western Psychological Services.

Losh, M., Adolphs, R., Poe, M. D., Couture, S., Penn, D., Baranek, G. T., \& Piven, J. (2009). Neuropsychological Profile of Autism and the Broad Autism Phenotype. Archives of General Psychiatry, 66, 518-526. https://doi.org/10.1001/archgenpsychiatry.2009.34

Mahone, E. M., Powell, S. K., Loftis, C. W., Goldberg, M. C., Denckla, M. D., \& Mostofsky, S. H. (2006). Motor Persistence and Inhibition in Autism and ADHD. Journal of International Neuropsychological Society, 12, 622-631.

https://doi.org/10.1017/s1355617706060814

Matsuura, N., Ishitobi, M., Arai, S., Kawamura, K., Asano, M., Inohara, K., Narimoto, T., Wada, Y., Hiratani, M., \& Kosaka, H. (2014). Distinguishing between Autism Spectrum Disorder and Attention Deficit Hyperactivity Disorder by Using Behavioral Checklists, Cognitive Assessments, and Neuropsychological Test Battery. Asian Journal of Psychiatry, 12, 50-57.

Mattila, M.-L., Hurtig, T., Haapsamo, H., Jussila, K., Kuusikko-Gauffin, S., Kielinen, M., Linna S. L., Ebeling, H., Bloigu, R., Joskitt, L., Pauls, D. L., \& Moilanen, I. (2010). Comorbid Psychiatric Disorders Associated with Asperger Syndrome/High-Functioning Autism: A Community- and Clinic-Based Study. Journal of Autism and Developmental Disorders, 40, 1080-1093. https://doi.org/10.1007/s10803-010-0958-2

Narzisi, A., Muratori, F., Calderoni, S., Fabbro, F., \& Urgesi, C. (2013). Neuropsychologi- 
cal Profile in High Functioning Autism Spectrum Disorders. Journal of Autism and Developmental Disorders, 43, 1895-1909. https://doi.org/10.1007/s10803-012-1736-0

Minshew, N. J., \& Goldstien, G. (2001). The Pattern of Intact and Impaired Memory Functions in Autism. Journal of Child Psychology and Psychiatry and Allied Disciplines, 42, 1095-1101. https://doi.org/10.1111/1469-7610.00808

O'shea, A. G., Fein, D. A., Cillesen, A. H. N., Klin, A., \& Schltz, R. T. (2005). Source Memory in Children with Autism Spectrum Disorders. Developmental Neuropsycholoy, 27, 337-360. https://doi.org/10.1207/s15326942dn2703_3

Ozonoff, S., Cook, I., Coon, H., Dawson, G., Joseph, R. M., Klin, A., \& Pennington, B. F. (2004). Performance on Cambridge Neuropsychological Test Automated Battery Subtests Sensitive to Frontal Lobe Functioning in People with Autistic Disorder: Evidence from the Collaborative Programs of Excellence in Autism Network. Journal of Autism and Developmental Disorders, 34, 139-150. https://doi.org/10.1023/B:JADD.0000022605.81989.cc

Planche, P., \& Lemonnier, E. (2012). Children with High-Functioning Autism and Asperger's Syndrome: Can We Differentiate Their Cognitive Profiles? Research in Autism Spectrum Disorders, 6, 939-948.

Purvis, K. L., \& Tannock, R. (1997). Language Abilities in Children with Attention Deficit Hyperactivity Disorder, Reading Disabilities, and Normal Controls. Journal of Abnormal Child Psychology, 25, 133-144. https://doi.org/10.1023/A:1025731529006

Reiersen, A. M., \& Todd, R. D. (2008). Co-Occurrence of ADHD and Autism Spectrum Disorders: Phenomenology and Treatment. Expert Review of Neurotherapeutics, 8, 657-669. https://doi.org/10.1586/14737175.8.4.657

Rizzutti, S., Sinnes, E. G., Scaramuzza, L. F., Freitas, L., Pinheiro, D., Palma, S. M., Mello, C. B., Miranda, M. C., Bueno, O. F., \& Muszkat, M. (2008). Clinical and Neuropsychological Profile in a Sample of Children with Attention Deficit Hyperactivity Disorders. Arquivos de Neuropsiquiatria, 66, 821-827.

https://doi.org/10.1590/S0004-282X2008000600009

Rommelse, N. N., Franke, B., Geurts, H. M., Hartman, C. A., \& Buitelaar, J. K. (2010). Shared Heritability of Attention Deficit Hyperactivity Disorder and Autism Spectrum Disorder. European Child and Adolescent Psychiatry, 19, 281-295.

https://doi.org/10.1007/s00787-010-0092-x

Ronald, A., Simonoff, E., Kuntsi, J., Asherson, P., \& Plomin, R. (2008). Evidence for Overlapping Genetic Influences on Autistic and ADHD Behaviours in a Community Twin Sample. The Journal of Child Psychology and Psychiatry, 49, 535-542. https://doi.org/10.1111/j.1469-7610.2007.01857.x

Rucklidge, J., \& Tannock, R. (2002). Neuropsychological Profiles of Adolescents with ADHD: Effects of Reading Difficulties and Gender. Journal of Child Psychology and Psychiatry, 43, 988-1003. https://doi.org/10.1111/1469-7610.00227

Rumsey, J. M., \& Hamburger, S. D. (1990). Neuropsychological Divergence of High-Level Autism and Severe Dyslexia. Journal of Autism and Developmental Disorders, 20, 155-168. https://doi.org/10.1007/BF02284715

Rumsey, J. M., \& Hamburger, S. D. (1988). Neuropsychological Findings in High-Functioning Men with Infantile Autism, Residual State. Journal of Clinical and Experimental Neuropsychology, 10, 201-221. https://doi.org/10.1080/01688638808408236

Saalasti, S., Lepistö, T., Toppila, E., Kujala, T., Laakso, M., Nieminen-von Wendt, T., \& Jansson-Verkasalo, E. (2008). Language Abilities of Children with Asperger Syndrome. Journal of Autism and Developmental Disorders, 38, 1574-1580.

https://doi.org/10.1007/s10803-008-0540-3

Schmidt, G. L., Kopelioff, L., Winterrowd, E., Pennington, B. F., Hepburn, S. L., \& Rojas, 
D. C. (2008). Impairments in Phonological Processing and Non-Verbal Intellectual Function in Parents of Children with Autism. Journal of Clinical and Experimental Neuropsychology, 30, 557-567. https://doi.org/10.1080/13803390701551225

Sergeant, J. A., Geurts, H., \& Oosterlaan, J. (2002). How Specific Is a Deficit of Executive Functioning for Attention-Deficit/Hyperactivity Disorder? Behavioural Brain Research, 130, 3-28.

Sinzig, J., Bruning, N., Morsch, D., \& Lehmkuhl, G. (2008a). Attention Profiles in Autistic Children with and without Comorbid Hyperactivity and Attention Problems. Acta Neuropsychiatrica, 20, 207-215. https://doi.org/10.1111/j.1601-5215.2008.00292.x

Sinzig, J., Morsch, D., Bruning, N., Schmidt, M. H., \& Lehmkuhl, G. (2008b). Inhibition, Flexibility, Working Memory and Planning in Autism Spectrum Disorder with and without Comorbid ADHD Symptoms. Child and Adolescent Psychiatry and Mental Health, 2, 4. https://doi.org/10.1186/1753-2000-2-4

Takeuchi, A., Ogino, T., Hanafusa, K., Morooka, T., Oka, M., Yorifuji, T., \& Ohtsuka, Y. (2013). Inhibitory Function and Working Memory in Attention Deficit/Hyperactivity Disorder and Pervasive Developmental Disorders: Does a Continuous Cognitive Gradient Explain ADHD and PDD Traits? Acta Medica Okayama, 67, 293-303.

Taurines, R., Schwenck, C., Westerwald, E., Sachse, M., Siniatchkin, M., \& Freitag, C. (2012). ADHD and Autism: Differential Diagnosis or Overlapping Traits? A Selective Review. Attention Deficit Hyperactivity Disorders, 4, 115-139. https://doi.org/10.1007/s12402-012-0086-2

Taylor, D., Paton, C., \& Shitij, K. (2012). The Maudsley Prescribing Guidelines in Psychiatry. West Sussex: Wiley-Blackwell.

Tager-Flusberg, H. (2004). Strategies for Conducting Research on Language in Autism. Journal of Autism and Developmental Disorders, 34, 75-80. https://doi.org/10.1023/B:JADD.0000018077.64617.5a

Turner, M. A. (1999). Generating Novel Ideas: Fluency Performance in High-Functioning and Learning Disabled Individuals with Autism. Journal of Child Psychology and Psychiatry, 40, 189-201. https://doi.org/10.1111/1469-7610.00432

Tye, C., Asherson, P., Ashwood, K. L., Azadi, B., Bolton, P., \& McLoughlin, G. (2014). Attention and Inhibition in Children with ASD, ADHD and Co-Morbid ASD + ADHD: An Event-Related Potential Study. Psychological Medicine, 44, 1101-1116. https://doi.org/10.1017/S0033291713001049

Tsal, Y., Shalev, L., \& Mevorach, C. (2005). The Diversity of Attention Deficits in ADHD: The Prevalence of Four Cognitive Factors in ADHD versus Controls. Journal of Learning Disabilities, 38, 142-157. https://doi.org/10.1177/00222194050380020401

Van der Meer, J. M., Oerlemans, A. M., Van Steijn, D. J., Lappenschaar, M. G., De Sonneville, L. M., Buitelaar, J. K., \& Rommelse, N. N. (2012). Are Autism Spectrum Disorder and Attention-Deficit/Hyperactivity Disorder Different Manifestations of One Overarching Disorder? Cognitive and Symptom Evidence from a Clinical and Population-Based Sample. Journal of American Academy of Child and Adolescent Psychiatry, 51, 1160-1172.

Verté, S., Geurts, H. M., Roeyers, H., Oosterlaan, J., \& Sergeant, J. A. (2006). Executive Functioning in Children with an Autism Spectrum Disorder: Can We Differentiate within the Spectrum? Journal of Autism and Developmental Disorders, 36, 351-372. https://doi.org/10.1007/s10803-006-0074-5

Wechsler, D. (1991). Wechsler Intelligence Scale for Children (3rd ed., WISC-III). New York, NY: Psychological Corporation. 
Whitehouse, A. J. O., Barry, J. G., \& Bishop, D. V. M. (2008). Further Defining the Language Impairment of Autism: Is There a Specific Language Impairment Subtype? Journal of Communication Disorders, 41, 319-346.

Willcutt, E. G., Doyle, A. E., Nigg, J. T., Faraone, S. V., \& Pennington, B. F. (2005). Validity of the Executive Function Theory of Attention-Deficit/Hyperactivity Disorder: A Meta-Analytic Review. Society of Biological Psychiatry, 57, 1336-1346.

Williams, D. L., Goldstein, G., \& Minshew, N. J. (2006a). Neuropsychological Functioning in Children with Autism: Further Evidence for Disordered Complex Information Processing. Child Neuropsychology, 12, 279-298.

https://doi.org/10.1080/09297040600681190

Williams, D., Goldstein, G., \& Minshew, N. (2006b). The Profile of Memory Function in Children with Autism. Neuropsychology, 20, 21-29.

https://doi.org/10.1037/0894-4105.20.1.21

World Health Organization (WHO) (1993). The ICD-10 Classification for Mental Behavioural Disorders: Diagnostic Criteria for Research. Geneva: World Health Organization.

Yerys, B. E., Wallace, G. L., Sokoloff, J. L., Shook, D. A., James, J. D., \& Kenworthy, L. (2009). Attention Deficit/Hyperactivity Disorder Symptoms Moderate Cognition and Behavior in Children with Autism Spectrum Disorders. Autism Research, 2, 322-333. https://doi.org/10.1002/aur.103

Youngwirth, S. D., Harvey, E. A., Gates, E. C., Hashim, R. L., \& Friedman-Weieneth, J. L. (2007). Neuropsychological Abilities of Preschool-Aged Children Who Display Hyperactivity and/or Oppositional-Defiant Behaviour Problems. Child Neuropsychology, 13, 422-443. https://doi.org/10.1080/13825580601025890

Submit or recommend next manuscript to SCIRP and we will provide best service for you:

Accepting pre-submission inquiries through Email, Facebook, LinkedIn, Twitter, etc. A wide selection of journals (inclusive of 9 subjects, more than 200 journals) Providing 24-hour high-quality service User-friendly online submission system Fair and swift peer-review system Efficient typesetting and proofreading procedure Display of the result of downloads and visits, as well as the number of cited articles Maximum dissemination of your research work

Submit your manuscript at: http://papersubmission.scirp.org/

Or contact psych@scirp.org 